\title{
Rested, friendly, and engaged:
}

\section{The role of daily positive collegial interactions at work}

\author{
Eugenia McGrath, Auckland University, NZ \\ Helena Cooper-Thomas, Auckland University, NZ \\ Eva Garrosa, Autonomous University of Madrid, Spain \\ Ana Isabel Sanz Vergel, Norwich Business School, University of East Anglia \\ $\&$ \\ Gordon Cheung, Auckland University, NZ
}

Paper accepted in Journal of Organizational Behavior 


\begin{abstract}
This diary study examined within-person effects of positive work and off-work experiences on daily engagement levels. Assessing the gain cycle assumption of conservation of resources theory, we investigated the relationship of night-time recovery and subsequent resources including elevated sleep quality and morning positive affect; the relationship of morning positive affect with positive collegial interactions and subsequent engagement; and the relationship of engagement with night-time recovery. Sixty-nine employees from various occupations completed surveys three times per day, over five consecutive working days. Multilevel analyses revealed that sleep quality positively predicted morning positive affect, which in turn predicted engagement directly and also indirectly through having positive interactions with colleagues. Engagement positively predicted night-time recovery, while night-time recovery was not related to sleep quality or morning positive affect the next day. The results suggest that on days when individuals have a good night's sleep, they feel more positive, bring this positivity to their workplace, reach out to their workplace colleagues, and are in turn more likely to be engaged in their work. Additionally, on days when individuals experience higher levels of positive collegial interactions at work and in turn higher engagement, they are likely to experience better recovery.
\end{abstract}


In today's volatile economic environment, organizations seek a competitive advantage via employees, and work engagement is central to this. Defined as "a positive, fulfilling workrelated state of mind" (p.74), engaged employees are energetic and resilient in the face of workrelated obstacles; are enthusiastic about their work; and fully concentrate on their work (Schaufeli, Salanova, González-Romá, \& Bakker, 2002). Engagement has been linked to improved customer satisfaction and financial returns at the organizational level, and job performance and wellbeing at the employee level (Hakanen \& Schaufeli, 2012; Salanova, Agut, \& Peiro, 2005; Xanthopoulou, Bakker, Demerouti, \& Schaufeli, 2009b).

Due to the benefits of engagement, research has focused on identifying factors that foster engagement (Garrosa, Moreno-Jiménez, Rodríguez-Muñoz, \& Rodríguez-Carvajal, 2011). Recovery is a potential resource predicting engagement and - while there is an established reciprocal relationship between these two phenomena (Sonnentag, 2003; Sonnentag, Mojza, Demerouti, \& Bakker, 2012) - the mechanisms explaining the relationship of recovery as antecedent to engagement are yet to be examined. We address this gap by proposing an interpersonal mechanism explaining this relationship.. To do so, based on conservation of resources (COR) theory (Hobfoll, 1989, 2002) and broaden-and-build (B\&B) theory (Fredrickson, 2004), we first identify the conditions leading to these positive interactions (i.e., recovery the previous night, sleep quality and morning positive affect), and then analyze whether positive affect may broaden employees' awareness of others, increasing their willingness to approach. This is turn generates energizing resources, increasing work engagement levels as reported in the evening. We close the cycle by analyzing the mediating effect of engagement on the relationship between positive interactions with colleagues and recovery experiences during non-work time. 
This study contributes to extant research in four ways. First, drawing on COR theory (Hobfoll, 1989, 2002) and B\&B theory (Fredrickson, 2004), we assess the cumulative nature of resources at a day level, whereby existing resources are used to gain additional resources. With research acknowledging the importance of workplace bonds (Freeney \& Fellenz, 2013), and social support (Xanthopoulou, Bakker, Demerouti, \& Schaufeli, 2009a), we advance engagement research by investigating positive collegial interactions as a novel and potentially important interpersonal resource predicting engagement. Second, we extend research on positive morning experiences and the subsequent accumulation of resources at work to investigate new relationships between constructs - in this case positive affect with positive collegial interactions and engagement. Third, we extend research on the work-home interface by examining the relationship of engagement across four domains of recovery experiences after work. Fourth, our study advances research on engagement and recovery by examining these relationships over a 24-hour cycle (see Figure 1). Finally, we contend that an important contribution of this study is the replication and extension of previous findings regarding daily resource gains, since this advances theory and research (Kepes \& McDaniel, 2013).

\section{Theoretical Frameworks}

According to COR, individuals seek to obtain, protect, and maintain resources in order to enhance their wellbeing, and experience stress when their resources are depleted (Hobfoll, 1989, 2002). COR theory defines resources as "those objects, personal characteristics, conditions, or energies that are valued by the individual or that serve as a means for attainment of these objects, personal characteristics, conditions, or energies" (Hobfoll, 1989, p. 516). Research has identified that resources such as autonomy, optimism, colleague support and hope are essential determinants of employee wellbeing and engagement (Ouweneel, LeBlanc, \& Schaufeli, 2012; 
Ouweneel, LeBlanc, Schaufeli, \& vanWijhe, 2012; Xanthopoulou, Bakker, Heuven, Demerouti, \& Schaufeli, 2008). Resources do not exist in isolation but rather are suggested to operate as resource caravans: Once gained, resources generate additional resources which lead to further positive outcomes, resembling an accumulative gain cycle (Hobfoll, 2002; ten Brummelhuis \& Bakker, 2012a). Thus, people with greater resources aim to accumulate additional resources, including social support systems (Hobfoll, 2002), and sustain their efforts to achieve positive outcomes (Xanthopoulou et al. 2009a). For example, Xanthopoulou and colleagues (2009a) followed employees over 1.5 years; those who were optimistic and experienced work autonomy were more engaged over time and, in turn, crafted additional personal and job resources.

In the same vein, according to B\&B theory (Fredrickson, 2004), positive states broaden individuals' scope of attention, increasing their openness to explore the environment and approach people. Experiencing positive states results in attainment of resources (e.g., selfefficacy; Ouweneel, LeBlanc, \& Schaufeli, 2012) and goals (e.g., performance; Bakker \& Bal, 2010). This study integrates the broaden hypothesis of B\&B theory with the resource gain cycle tenet of COR theory, exploring the degree to which daily positive off-work experiences broaden individuals' awareness resulting in positive work experiences marked by higher levels of positive collegial interactions and engagement, and in turn, better recovery experiences at home.

\section{Hypothesis Development}

Recovery. Drawing on COR (Hobfoll, 2002), this research investigates the role of nighttime recovery as a resource that helps restore morning resources, specifically quality of sleep and PA. Over the last decade, research has examined the degree to which daily off-work recovery experiences, such as learning something new, relaxing, or engaging in sports activities, influence employee wellbeing and performance (Rook \& Zijlstra, 2006; ten Brummelhuis \& Bakker, 
2012b). For instance, on mornings when employees feel replenished, they experience higher levels of engagement (Sonnentag et al., 2012). While previous studies have examined morning recovery in association with work-related outcomes, in fact much of an employee's opportunity for recovery occurs in the evening after-work.

Recovery and sleep quality. Conceiving of evening recovery as a resource (Binnewies, Sonnentag, \& Mojza, 2009) and drawing on COR, we propose that on evenings when individuals experience better recovery, they will gain further resources through better sleep quality. A lack of resources, including stress and rumination, predict poor sleep quality and consequent fatigue (Âkerstedt, Kecklund, \& Axelsson, 2007; Fahlén et al., 2006). Given that sleep quality has an impact on how individuals start their day (Sonnentag, Binnewies, \& Mojza, 2008; Steptoe, Dockray, \& Wardle, 2009), exploring what evening experiences enhance sleep quality is crucial in advancing literature on resource replenishment, and also answers calls for considering how sleep quality impacts individuals at work (Sonnentag et al., 2008, 2012).

Hypothesis 1a: Night-time recovery experiences will be positively associated with sleep quality.

Sleep quality and positive affect. Sleep quality is a resource for individuals at the outset of their working day. Positive affect (PA) is a state of feeling and a marker of subjective wellbeing; it connotes being alert, inspired, happy, active, and determined (Binnewies \& Fetzer, 2010). Much research has focused on sleep problems, which are associated with negative experiences such as lower PA (Steptoe et al., 2009) and fatigue (Querstret \& Cropley, 2012). Less is known about the effects of good quality sleep as a resource for the day ahead, although initial findings have revealed associations with higher morning serenity and PA (Sonnentag et al., 2008). Extending on this, we propose sleep quality is a physical resource fostering gains in affective resources, specifically morning PA. 
Hypothesis $\mathbf{1 b}$ : Sleep quality will be positively associated with morning PA.

Recovery, positive affect and sleep quality. Recovery experiences enable resource replenishment (Binnewies et al., 2009). Consistent with COR, night-time recovery experiences may not only directly affect sleep quality (Hypothesis 1a), but also interrupt the depletion of resources and restore individuals' positive affective states. For instance, a study of German employees found that evening relaxation and mastery recovery experiences (e.g., learning something new) were positively linked with morning PA (Sonnentag et al., 2008). Hypothesis 1c: Night-time recovery experiences will be positively related to morning PA.

Additionally, drawing on COR which posits that resource gain is accompanied by positive emotions (Hobfoll, 2002), we hypothesize that following evenings with a higher degree of recovery activities (e.g., psychological detachment, relaxation), individuals will experience higher PA the following morning indirectly through sleep quality (Hypothesis 1d).

Hypothesis 1d: The relationship between night-time recovery experiences and morning PA will be mediated by sleep quality.

\section{Positive affect and positive collegial interactions.}

Fredrickson's B\&B (2004) theory proposes that positive states broaden people's scope of attention, increasing their willingness to explore the environment and connect with others. Drawing on this, we explore the role of positive morning states in facilitating positive collegial interactions at work. Given working individuals spend roughly a third of their time in the workplace, interpersonal interaction is almost inevitable.

Interaction can take two forms: negative interactions such as workplace incivility which harm well-being (Lim, Cortina, \& Magley, 2008), and positive interactions such as social support and friendships which fulfill basic human needs and promote well-being (Dimotakis, 
Scott, \& Koopman, 2011; Ryan \& Deci, 2000). Positive interactions with colleagues and friends at work can be conceptualized as a social resource (Xanthopoulou, Bakker, Demerouti, \& Schaufeli, 2012). In contrast with social support where individuals are passive recipients (Bowling, Beehr, \& Swader, 2004), positive collegial interactions require a degree of awareness and active involvement (Heaphy \& Dutton, 2008), denoting a more positive action-oriented construct. Here, we define positive collegial interactions as an enjoyable, collegial focus on work, including initiating contact, solving problems, and enjoying the company of colleagues.

Thus, based on $\mathrm{COR}$ and $\mathrm{B} \& \mathrm{~B}$, and contributing to the literature on different aspects of positive relationships and connections at work (Methot, LePine, Podsakoff, \& Christian, 2016), we explore the role of morning positive affect as a personal resource that stimulates individuals to seek out positive collegial interactions. Experiences of positive affective states are associated with an increase in more general social resources (Xanthopoulou et al., 2009a). For example, underscoring the cumulative role of resources, a study at a Dutch engineering and electronics company showed that individuals who felt self-efficacious experienced higher levels of social support (Xanthopoulou, Bakker, Demerouti, \& Schaufeli, 2007).

Hypothesis 2a: Morning PA will be positively associated with day-level positive collegial interactions.

In agreement with COR, Heaphy and Dutton (2008) emphasized the potential benefits of workplace bonds. They proposed that positive interactions generate physiological resources which may provide the physical energy required for engagement. Thus, supportive resources are likely to be motivational, foster learning and personal growth, aid in achieving work-related goals (Bakker \& Demerouti, 2007), and may fulfill individuals' need to belong through experiencing positive collegial interactions (Baumeister \& Leary, 1995). In a daily study of 
European flight attendants, fluctuations in colleague support predicted engagement (Xanthopoulou et al., 2008; see also Freeney \& Fellenz, 2013; Xanthopoulou et al., 2009b). Thus, positive collegial interactions may similarly serve as a resource that precedes work engagement.

Hypothesis $2 \boldsymbol{b}$ : Day-level positive collegial interactions will be positively associated with daylevel engagement.

Positive affect, positive collegial interactions, and engagement. Positive emotions are a resource which may help gain other resources (COR), broaden awareness, and help to build new resources $(B \& B)$. Sharing positive emotions with colleagues buffers the effects of work pressure on exhaustion, whereas expressing negative emotions reduces feeling recovered after a work break (Sanz-Vergel, Demerouti, Moreno-Jiménez, \& Mayo, 2010). Furthermore, positive emotions - including self-efficacy, context-free vigor, and PA - are associated with engagement (Garrosa et al., 2011; ten Brummelhuis \& Bakker, 2012b). For example, a longtitudinal study of Spanish teachers demonstrated a gain cycle of resources over time whereby higher levels of selfefficacy predicted positive affect (enthusiasm), and in turn enhanced engagement eight months on (Salanova, Llorens, \& Schaufeli, 2011; see also ten Brummelhuis \& Bakker, 2012b).

Aligning with COR, previous research has shown that resource gain cycles can include positive emotions that predict work engagement (Ouweneel et al., 2012). In the same way, positive collegial interactions may provide durable resources that can be drawn on multiple times to facilitate resource gain (Bakker \& Xanthopoulou, 2009; Westman, 2001). Building on these notions, we examine the accumulation of resources over each working day. Hypothesis 2c: Morning PA will be positively associated with day-level engagement. 
Hypothesis 2d: The relationship between morning PA and day-level engagement will be mediated by day-level positive collegial interactions.

Engagement and recovery. According to COR, resource depletion over the course of the day is associated with the onset of stress. Engaged employees are energetic and able to mobilize resources when required (Bakker, Albrecht, \& Leiter, 2011), avoiding resource depletion (Gorgievski, Bakker, \& Schaufeli, 2010). However, “overengagement” may have adverse effects such as workaholism, involving taking work home (Bakker et al., 2011), which could lead to work-home interference (Halbesleben, Harvey, \& Bolino, 2009) and hinder recovery. Other research has linked morning recovery with engagement during the day, which in turn predicted feelings of recovery after work (Sonnentag et al., 2012). This study positions engagement as a work-related energizing resource (Sonnentag et al., 2012), which is likely to stimulate the gain of other resources, including off-work resources such as recovery experiences.

Hypothesis 3: Day-level engagement will be positively associated with night-time recovery experiences.

\section{Method}

\section{Sample}

Participants were 122 employees from various occupations in New Zealand (NZ) and the United States of America (US). The response rate is unknown for those who received but did not click on the participation link. Of the 122 individuals, 101 provided core general level survey data. Eighty-four completed online and 17 completed paper-based surveys. Seventy-two (59\% response rate) continued on to provide data that could be matched with general and day-level surveys using a unique self-generated code. Following other diary research, data from participants who completed less than two full days of daily matched sets of surveys (morning, 
afternoon, night-time) were discarded (Dimotakis et al., 2011). The final sample consisted of 69 individuals (final response rate 57\%) with 336 observations ( $M=4.86$ observations).

Fifty-four percent of the participants were from NZ. Of the overall sample of US and NZ participants, sixty-two percent of the respondents were female and the mean age of the sample was 38 years $(S D=10.91)$, ranging from 22 to 73 . The majority of the participants were Caucasian/NZ European (76.8\%), with $8.7 \%, 11.6 \%$ and $1.4 \%$ identifying as Asian, other, and Pasifika $^{1}$, respectively. Participants worked in a broad range of professional backgrounds including tourism $(21.7 \%)$, government $(15.9 \%)$, professional services $(10.1 \%)$, healthcare $(8.7 \%)$, and education $(7.2 \%)$ among others. Mean job tenure was 5.3 years $(S D=4.72)$; with a mean of 18.04 years work experience $(S D=11.72)$. Thirty-five percent of the participants had a university education, 29\% had a Trade Diploma or Certificate, and 36\% had a lower vocational education. Most participants $(56.5 \%)$ held a team-member position, or else a supervisor position $(21.7 \%)$, middle management $(8.7 \%)$, or company executive and senior management $(11.6 \%)$.

\section{Procedure}

Participation was voluntary, using email and word-of-mouth snowball recruitment (Gardner, 2009). Participants were required to be 16 years or older and work 30 or more hours per week. Participation could be completed either via: 1) online survey or 2) paper survey. Research comparing quantitative (i.e., similar means and variances) and qualitative equivalence (i.e., construct validity) of paper-and-pencil and internet data demonstrates that these methods are generally equivalent (Weigold, Weigold, \& Russell, 2013). The surveys comprised general, morning, afternoon, and night-time versions. Participants were offered entry into a prize-draw for grocery vouchers as an incentive, and also feedback about the study results. 
Participants completed the general questionnaire, then daily questionnaires three times per day over five consecutive working days. Instructions emphasized the importance of completing the daily surveys at three distinct time points: 1) morning (before work), 2) afternoon (after work), and 3) night (before bedtime). To maintain anonymity yet allow data matching across surveys, participants developed a memorable unique code comprised of the first three letters of their mother's maiden name and last four digits of their cellphone number.

\section{Measures}

Data were collected at the day and person level.

Day-level measures. Efforts were made to combat potential common method variance by measuring predictors and outcomes at different time points (Podsakoff, MacKenzie, \& Podsakoff, 2012). Daily surveys assessed day-level experiences of 1) sleep duration, sleep quality and PA in the morning, 2) positive collegial interactions in the late afternoon (after work), and 3) engagement and recovery at night before bed. We modified the measures for daily use by adding a similar initial item stem, which was "Today...” for engagement, "Today, I feel..." for PA, “Today, at work..." for interactions, and "Today, after work..." for recovery (see Breevaart et al., 2012). For day-level variables, Cronbach's alphas were computed for each of the five measurement occasions and then averaged (see Table 1, column 5).

Morning - Sleep Quality was assessed each morning by asking participants "Please evaluate your sleep quality last night" using a 6-point Likert rating scale $(1=$ very bad to $6=$ very good). The single item was based on Sonnentag et al.'s (2008) scale and closely followed the original Pittsburg Sleep Quality Index (Buysse, Reynolds III, Monk, Berman, \& Kupfer, 1989). Morning - PA was measured using Thompson's (2007) positive and negative affect schedule (PANAS) on a 5-point Likert scale $(1=$ no, it's not at all true to $5=$ yes, it's completely 
true). PA items are: Alert, inspired, determined, attentive, and active. Cronbach's alpha ranged from $.84-.91(M=.88)$.

Afternoon - Day-level positive collegial interactions was assessed using four items from Nielsen, Jex, and Adams' (2000) workplace friendship scale, rated on a 5-point Likert scale $(1=$ no, it's not at all true to $5=$ yes, it's completely true). Example items are "I got on well with my co-workers" and "I worked with my co-workers collectively to solve problems". Cronbach's alpha ranged from $.80-.91(M=.85)$.

Night - Day-level engagement was assessed by the nine-item version of the Utrecht Work Engagement Scale as a single measure (UWES; Breevart et al., 2012; Schaufeli, Bakker, \& Salanova, 2006). An example item is: "I was enthusiastic about my job". Items were scored on a 6-point rating scale $(1=$ no, it's not at all true to $6=$ yes, it's completely true). Cronbach's alpha ranged from $.92-.96(M=.94)$.

Night-Day-level recovery experiences were assessed by Sonnentag and Fritz's (2007) 16-item scale, containing four subscales each of four items. Example items are "I forgot about work" (detachment), "I did relaxing things" (relaxation), "I learned new things" (mastery experiences), and "I decided my own schedule" (control). Recovery was aggregated into one factor. Ratings used a 5-point Likert scale $(1=$ no, it's not at all true to $5=$ yes, it's completely true). A lagged variable was created for recovery ("recovery lag") in order to examine the relationship of night-time recovery with variables the following day. Cronbach's alpha ranged from $.91-.92(M=.91)$.

Day-level controls. Consistent with previous research (Sonnentag et al., 2008), we controlled for sleep duration in analyses that included sleep quality as a predictor, to ensure that variance in the outcome is attributed to previous night's sleep quality only. To assess sleep 
duration, morning surveys asked participants to report how many hours they had slept the previous night.

Day of week ("weekday", day 1-5) was included as a Level-1 predictor in all analyses to capture within-person fluctuations over time (Bliese \& Ployhart, 2002). Days were coded as Day $1=-2$, Day $2=-1$, Day $3=0$, Day $4=1$, Day $5=2$.

Person-level controls. Following current research on recovery and engagement, trait measures of PA, collegial interactions, recovery experiences, and engagement were included as person-level controls in the analyses to account for individual differences when predicting dayspecific variables (see Sonnentag \& Binnewies, 2013; ten Brummelhuis \& Bakker, 2012b). This controls for individuals' general tendencies that may impact their momentary states (Xanthopoulou et al., 2008); further reduces potential common method variance (Podsakoff et al., 2012); and acknowledges and integrates trait and state engagement (Breevaart et al., 2012).

Control variables were measured in the general survey. Scale items were identical to daylevel measures except for the prefix which read "Generally..." or "Generally at work...". The anchors for each scale were changed in order to reduce the risk of common method variance (Podsakoff et al., 2012). General PA was rated $1=$ never to $5=$ always $(\alpha=.61)$. Implications of this low reliability are discussed in Limitations. General collegial interaction was rated $1=$ strongly disagree to $5=$ strongly agree $(\alpha=.80)$. General engagement was rated $1=$ almost never to $6=$ always $(\alpha=.91)$. General recovery experiences were rated $1=\mathrm{I}$ do not agree at all to $5=\mathrm{I}$ fully agree $(\alpha=.88)$.

Country $(0=\mathrm{NZ}, 1=\mathrm{US})$ was included as a control during model building in order to examine possible cultural effects. Country was not a significant predictor nor did it improve model fit; it was therefore excluded from the final models. Demographic variables were 
measured and used to describe the sample. Because there is no theoretical rationale, they were not considered as controls (Spector \& Brannick, 2011).

\section{Data analysis procedure}

Our data are comprised of two levels, with repeated measurements at the day-level (Level 1: Weekday, sleep duration, sleep quality, PA, positive interactions, engagement and recovery), and measurements at the person-level (Level 2: Traits of day-level variables). Day-level data (within-person; $N=336$ ) are nested within person-level data (between-person; $N=69$ ). Multilevel linear modeling (MLM) is the recommended analysis method for such hierarchically structured data with two levels (Raudenbush \& Bryk, 2002). MLM was conducted through IBM SPSS Mixed Models, software version 21 for Windows.

Person-level predictors were centered around the grand mean and day-level predictors around their respective person mean. Person-mean centering of day-level predictors allows separation of between-person variability when interpreting results (Enders \& Tofighi, 2007).

The Monte Carlo Method for Assessing Mediation (MCMAM) was used to test mediation effects. MCMAM outperforms other methods (Selig \& Preacher, 2008) and provides confidence intervals for indirect effects (Preacher \& Selig, 2012). The R program was used to simulate random draws and compute the indirect effect, the product of $a^{*} b$, where $a$ is the effect of the IV $(x)$ on the mediator $(m)$ and $b$ is the effect of the mediator $(m)$ on the DV $(y)$, controlling for $x$ (Selig \& Preacher, 2008). Imputed parameter estimates and associated standard errors of $a$ and $b$ were used to simulate random draws from the $a$ and $b$ distributions and compute a $95 \%$ confidence interval (CI) based on 20,000 repetitions (Preacher \& Selig, 2012). The null hypothesis of no mediation is rejected when the $95 \%$ CIs do not include a zero (Selig \& Preacher, 2008). 


\section{Results}

\section{Preliminary Analyses}

Data were discarded for participants who did not complete two or more full days of observations. At the item-level, Little's MCAR test was nonsignficant for Level 1 and 2 variables, showing data to be missing completely at random (Newman, 2008). MLM has the ability to handle analyses with different patterns of missing data, hence we retained individuals with partial data (Heck, Thomas, \& Tabata, 2013). Analyses were repeated both with missing and with multiply-imputed data (Tabachnick \& Fidell, 2013) with no significant differences. We report analyses using missing (unimputed) data. Some nonnormality was observed, but transformations did not rectify this (Tabachnick \& Fidell, 2013). All variables were thus retained untransformed; implications are discussed in the Limitations. The model converged in all analyses, showing no evidence of multicollinearity. Outliers were examined at item-level using a top-down approach from Level 2 to Level 1 (Aguinis, Gottfredson, \& Joo, 2013). Six outliers were detected at Level 2, but removing outliers did not affect model fit and they were thus retained in reported analyses (Aguinis et al., 2013).

The intraclass correlation coefficient (ICC; $p$ ) was computed to determine the degree of variation attributed to the within- and between-person levels by partitioning out the variance in all day-level outcomes (Heck et al., 2013). The equation for the ICC (Hox, 2010) is:

$$
p=\sigma_{\text {between-goup variance }}^{2} /\left(\sigma_{\text {between-goup variance }}^{2}+\sigma_{\text {within-group variance }}^{2}\right) .
$$

Within-person variation was calculated by 1 - ICC and ranged from $32.2 \%$ (engagement) to $66.5 \%$ (sleep quality; see Table 1, column 6), warranting a multilevel approach. Table 1 presents means, standard deviations, Cronbach's alphas, 1-intraclass correlations (1-ICC) and correlations for all study variables. 
INSERT TABLE 1 ABOUT HERE

\section{Multilevel Analyses}

Building the model. Hypotheses were tested with a series of multilevel models using a built-up strategy (Raudenbush \& Bryk, 2002), starting with an unconditional Null model that included the intercept only. Weekday, sleep duration, and person-level variables were added in Model 1 as controls. In Model 2, day-level predictors were entered. Model fit was examined using the chi-square difference test $\left(\chi^{2}\right)$ by comparing each model to the previous using the $-2 \mathrm{x}$ log-likelihoods and obtaining the change in deviance $(\Delta \mathrm{D})$. Maximum likelihood estimation was used to produce parameter estimates necessary for deviance tests (Hox, 2010). Using a trial and error approach (Hox, 2010), we settled on a random intercept model with fixed Level 1 parameters since this fit the data better than a model with random slopes.

\section{Hypotheses Testing}

Hypothesis 1a proposed recovery at night-time is positively related to sleep quality the following morning (note that this uses "recovery lag"). Table 2 displays the results. Model 1 showed significant improvement over the Null model $(\Delta-2 \times \log =125.26, d f=2, p<.001)$, with weekday and sleep duration as significant predictors $(p<.001)$. When recovery lag was entered in Model 2 a significant improvement over Model 1 was observed $(\Delta-2 \times \log =226.20, d f=1, p$ $<.001)$ but recovery lag was nonsignificant $(p=.051)$. Hypothesis 1a was not supported.

As a measure of the effect size, pseudo $\mathrm{R}^{2}$ was calculated to obtain the explained variance at day (Level 1) and person (Level 2) using (Raudenbush \& Bryk 2002) equation:

$$
\mathrm{R}^{2}=\left(\sigma_{\text {null model }}^{2}-\sigma_{\text {model } 2}^{2}\right) / \sigma_{\text {null model }}^{2}
$$

Taken together, the control and predictor variables explained $44 \%$ of variance in sleep quality at the day-level $[(1.068-.598) / 1.068=.44]$. At the person level, the $\mathrm{R}^{2}$ value was negative. An 
“impossible $\mathrm{R}^{2}$ value" (Hox, 2010, p.72) such as this can occur in repeated measures design when within-person variance accounts for most of the variance (Heck et al., 2013).

\section{INSERT TABLE 2 ABOUT HERE}

Hypothesis $1 \mathrm{~b}$ predicted that sleep quality is positively associated with morning PA.

Table 3 shows the results. Model 1, which included weekday, sleep duration, and general level of PA as controls, showed significant improvement over the Null model $(\Delta-2 \times \log =31.96, d f=3$, $p<.001$ ), with sleep duration and general level of PA as strong predictors of morning PA ( $p<$ .001). With Level 1 predictors recovery lag and sleep quality entered into Model 2, model fit was significantly improved $(\Delta-2 \times \log =191.90, d f=2, p<.001)$. Sleep quality was a strong predictor of morning PA $(\gamma=.23, S E=.05, t=4.91, p<.001)$, supporting Hypothesis $1 \mathrm{~b}$. All control and predictor variables entered into the models explained $24.4 \%$ and $16.7 \%$ of variance in PA at dayand person-levels, respectively.

Hypothesis 1c proposed that recovery is positively related to morning PA; and Hypothesis 1d proposed that this relationship is mediated via sleep quality. Recovery lag was not a significant predictor of morning PA $(\gamma=.04, S E=.08, t=.52, p=.604)$, providing no support for Hypothesis 1c. A test of the mediation Hypothesis 1d required a significant relationship between recovery lag and sleep quality (H1a; Selig \& Preacher, 2008) which fell just short of significance $(p=.051)$. Hence mediation was not tested.

\section{INSERT TABLE 3 ABOUT HERE}

Hypothesis 2 a proposed that morning PA will be positively related to day-level positive collegial interactions. The results are presented in Table 4. Model 1 controlled for weekday and general level of collegial interaction and showed a significant improvement over the Null model $(\Delta-2 \times \log =41.52, d f=2, p<.001)$. General collegial interaction was a significant predictor of 
day-level interaction. Including morning PA as the Level 1 predictor in Model 2 improved model fit $(\Delta-2 \times \log =11.72, d f=1, p<.001)$, and morning PA was a significant predictor of afternoon collegial interaction $(\gamma=.13, S E=.06, t=2.31, p=.021)$, supporting Hypothesis $2 \mathrm{a}$. Together, all controls and predictors explained $3.6 \%$ and $48.5 \%$ of the variance in positive collegial interactions at day and person levels, respectively.

\section{INSERT TABLE 4 ABOUT HERE}

We predicted that positive collegial interactions (Hypothesis 2b) and morning PA (Hypothesis 2c) are positively related to day-level engagement. Table 5 presents the results. Adding weekday and general level of engagement to Model 1 showed a better model fit than the Null model $(\Delta-2 \times \log =56.09, d f=2, p<.001)$, with general level of engagement a strong predictor of day-level engagement. Entering day-level predictors PA and interactions into Model 2 resulted in a significantly better fit over Model $1(\Delta-2 \times \log =94.60, d f=2, p<.001)$. Both PA $(\gamma=.48, S E=.06, t=7.76, p<.001)$ and positive collegial interactions $(\gamma=.22, S E=.07, t=3.28$, $p=.001)$ were significant predictors of day-level engagement. Hypotheses $2 \mathrm{~b}$ and $2 \mathrm{c}$ were supported. All control and predictor variables accounted for $26.1 \%$ and $59.7 \%$ of variance in day-level engagement at day and person levels, respectively.

\section{INSERT TABLE 5 ABOUT HERE}

Hypothesis $2 \mathrm{~d}$ predicted morning PA $(x)$ is indirectly related to day-level engagement $(y)$ via day-level workplace interactions $(m)$. Hypothesis $2 \mathrm{c}$ provides the conditions for mediation, and hence we tested for indirect effects. Table 6 presents parameter estimates, their standard errors, direct and indirect effects and CIs. The indirect effect of morning PA on day-level engagement, via day-level workplace interactions was .03, and the CIs for this estimate did not contain a zero, supporting Hypothesis $2 \mathrm{~d}$. 
INSERT TABLE 6 ABOUT HERE

In Hypothesis 3, we proposed that day level engagement is positively related to nighttime recovery. The results in Table 7 show that Model 1 with weekday and general level of recovery variables as controls provided a better model fit than the Null model $(\Delta-2 \times \log =$ 41.39, $d f=2, p<.001)$. General recovery was significantly related to night-time recovery, while weekday was nonsignificant. Model 2 showed a further improvement over Model $1(\Delta-2 \times \log =$ 23.17, $d f=1, p<.001$ ), with day-level engagement a significant predictor of night-time recovery $(\gamma=.16, S E=.05, t=3.12, p=.002)^{2}$, supporting Hypothesis 3. All control and predictor variables accounted for $5.3 \%$ and $49.3 \%$ of variance in night-time recovery at day and person levels, respectively. Figure 1 depicts the overall results.

\section{INSERT TABLE 7 ABOUT HERE}

\section{INSERT FIGURE 1 ABOUT HERE}

\section{Supplementary Analyses}

Two supplementary analyses were conducted to test mediation effects inherent in the model. Sleep quality was positively related to PA (H1b) which in turn positively related to positive collegial interactions ( $\mathrm{H} 2 \mathrm{a})$ and engagement $(\mathrm{H} 2 \mathrm{c})$; engagement was in turn positively related to recovery $(\mathrm{H} 3)$. Consistent with COR, we would expect that PA mediates between the resource of sleep quality and the gain of additional resources at work, as positive interactions and engagement. Additionally, the accumulation of resources may continue as positive interactions facilitate recovery through engagement as a mediator ${ }^{3}$. Results are presented in Table 6. No CI path contained a zero, confirming the indirect effect of sleep quality on both engagement and interactions via PA, and the indirect effect of positive interactions on recovery via engagement.

\section{Discussion}


Drawing on the gain process of COR theory (Hobfoll, 2002) and the broaden aspect of B\&B theory of positive emotions (Fredrickson, 2004), this diary study advances research on the relationships between daily resources, namely recovery experiences, sleep quality, PA, positive interactions with colleagues and engagement, within a 24-hour cycle. Consistent with hypotheses, sleep quality predicted morning PA (H1b), although night recovery did not have lagged effects (H1a and H1c). Morning PA was positively related to positive collegial interactions ( $\mathrm{H} 2 \mathrm{a})$, and engagement throughout the day both directly $(\mathrm{H} 2 \mathrm{c})$ and indirectly through collegial interactions (H2b and $\mathrm{H} 2 \mathrm{~d}$ ). Furthermore, daily engagement was positively related to night-time recovery experiences (H3). While our findings do not establish causality, they suggest that, on a given day when individuals wake up replenished, they feel more positively than they do on average. This positivity facilitates more constructive and enjoyable interactions with their colleagues at work, and in turn higher engagement. Additionally, the current findings imply that workday engagement fosters better evening recovery.

\section{Research contributions}

Sleep quality is substantiated as an important personal resource predicting greater levels of PA. This adds to the nascent literature on the positive, restorative benefits of good quality sleep for PA (Sonnentag \& Binnewies, 2013; Sonnentag et al., 2008). Our supplementary analyses indicated that sleep quality is related to both engagement and collegial interactions through morning PA, and that positive collegial interactions are related to recovery experiences through daily engagement. These findings are consistent with COR, which posits that resources accumulate in the presence of other resources (Hobfoll, 2002). The novel connection of collegial interactions with recovery via engagement complements research that positive social interactions are associated with physiological responses associated with recovery, such as healthier cortisol 
rhythms and return of cardiovascular systems to resting levels after work (Heaphy \& Dutton, 2008). Moreover, it supports the interpersonal aspect of B\&B theory: On mornings when individuals feel more PA, their awareness is broadened, thus they are more likely to approach colleagues and have positive interactions, which is subsequently associated with higher engagement. On this evidence, PA and positive collegial interactions appear to act as resources with motivational potential, fostering engagement. These results extend research on the workhome interface which has shown variants of positive morning states, such as feeling replenished, hopeful, and vigorous, facilitate further resource generation and subsequent engagement throughout the day (Ouweneel et al., 2012; Sonnentag, 2003; ten Brummelhuis \& Bakker, 2012b). Our finding that positive collegial interactions were related to engagement is consistent with research showing that work relationships, such as experiencing social support, are related to positive outcomes (Dimotakis et al., 2011; Xanthopoulou et al., 2008). Overall, constructive and enjoyable workplace interactions with colleagues are supported as an important resource (Heaphy \& Dutton, 2008) with the potential to foster daily work engagement. A further unique feature of this study is the mediating effect of engagement in the relationship between positive interactions at work and recovery. The role of social mechanisms has only recently begun to be recognized (Heaphy \& Dutton, 2008; Methot et al., 2016) and, as the current evidence suggests, they are integral in the recovery process. To our knowledge, this study is the first to examine positive collegial interactions in this way.

These results suggest that engagement not only results from positive resources, but may also have individual wellbeing benefits. Specifically, in line with our predictions, on days when individuals experienced higher engagement levels, they reported higher recovery in the evening. Previous research has found both negative (Halbesleben et al., 2009) and positive effects (Bakker 
et al., 2014) of engagement on the work-home interface. Our findings support a positive relationship and extend this by incorporating all four recovery experiences in measuring recovery (c.f., Sonnentag et al., 2012). Thus, on days when employees are highly engaged, they also report higher levels of recovery experiences in the evening by detaching from work, relaxing, being in control of their own time, or learning new skills.

Focusing on two surprising findings in our study, recovery at night-time was not related to either sleep quality or PA the next morning. This contrasts with research where recovery experiences have been associated with morning affective states (Sonnentag et al., 2008). Several factors could explain our null findings. Some evening activities or experiences may occur that negate the relationship between night-time recovery and both morning affect and sleep quality. Affect at bedtime (Sonnentag \& Binnewies, 2013) or work-related technology use before bed may attenuate any benefits of recovery experiences for sleep and morning PA. For example, smartphone users experience difficulties participating in recovery activities (Derks, ten Brummelhuis, Zecic, \& Bakker, 2014). For quality of sleep, other antecedents may outweigh the benefits of recovery, such as stress (Âkerstedt et al., 2007) which elevates night-time cortisol (Rodenbeck, Huether, Rüther, \& Hajak, 2002). Given the importance of sleep quality to work (Kucharczyk, Morgan, \& Hall, 2012), research is needed to identify factors that impede or facilitate individuals from accruing sleep as a resource for the new day. In the meantime, our results imply that a good quality sleep matters, serving as a starting point for a day of positive work and off-work experiences that operate in an upward gain cycle.

\section{Limitations}

The use of self-report data is associated with common method variance. We followed several of Podsakoff and colleagues' (2012) recommendations to reduce this. First, rating anchor 
points for the general and daily surveys differed. For example, all daily measures had negative anchor points "no, it's not true at all”, while general measures had other anchor points that variously read: "I do not agree at all”, “almost never”, and "strongly disagree”. Second, by person-centering within-person variables, we eliminated potential influence from individual differences (Hox, 2010). Third, we controlled for the baseline of each dependent variable to ensure that we examined daily effects and not general tendencies. Fourth and finally, measurement design ensured that most predictor and criterion variables were measured at different time points each day (morning, afternoon, evening).

A second issue is that, while there were temporal intervals between measurements, the causality and direction of the relationships examined cannot be established (Antonakis, Bendahan, Jacquart, \& Lalive, 2010). Other temporal measurements of variables are possible and may have yielded different results.

Related to this issue, daily engagement and night-time recovery experiences were measured at the same time point, potentially inflating this relationship. However, negative affect (NA) was also included in the night-time survey in order to control for method bias, but analyses with and without the inclusion of NA yielded similar results. Furthermore, the time reference points for engagement and recovery differed: Engagement items referred to the working day and recovery items referred to non-work time.

Third, the general (trait) measure of PA used as a control variable in one hypothesis (Hypothesis 1b) had low reliability (.61). Yet when used at a daily level, these PA items showed good reliabilities $(M=.88)$. The implication of this is that, when predicting daily PA with daily sleep quality, not all variance in trait-level PA was removed from daily PA. This scale has 
previously shown good reliability and validity (Schütze, Rees, Preece, \& Schütze, 2010).

Nonetheless, future research should consider using a longer affect measure to improve reliability.

\section{Future Research}

In this research, we measured recovery across four domains covering relaxation, mastery, control, and psychological detachment. These experiences may contribute differently to actual recovery from work. For example mastery - "learning something new" - may be considered "work" to one individual but "recovery" to another. Examining the relative contributions of these types of recovery, perhaps for different types of work or worker, would enable the provision of practical advice to help employees restore their resources after the working day.

We conceptualized and measured positive collegial interactions as an enjoyable and constructive variable. Individuals may seek out interactions at work for other reasons beyond daily PA, for example after experiencing NA, incivility, or meeting their need to belong. Moreover, even enjoyable interactions can have a negative side due to friendship maintenance responsibilities (Methot et al., 2016) which may detract from engagement and subsequent performance. Our research only whets the appetite for more research into workplace interactions.

A recent development in affective state research is motivational intensity, which is the strength to move towards a goal (Harmon-Jones, Gable, \& Price, 2013). When PA is low in motivational intensity - a positive state is induced after a goal has been achieved (e.g., happiness after a pleasant interaction) - cognitive scope broadens. In contrast, when PA is high in motivational intensity - a specific desire or goal toward something (e.g., desire for an engaging day) - this narrows cognitive scope (Harmon-Jones et al., 2013). An intriguing question is whether PA differs in motivational intensity in predicting engagement. Perhaps low intensity PA, for example as experienced on mornings after having a pleasant breakfast, may broaden 
awareness and cognition facilitating positive collegial interactions and higher engagement levels. Alternatively, reading a news item relevant to work over breakfast may result in high intensity PA, which may have more direct links to engagement, bypassing collegial interactions. Finding out what specifically drives positive morning states, and their intensity, could be crucial to understanding what it is that "resets" the previous day.

Our research investigated the path from PA to positive collegial interactions and engagement. It is possible that these relationships are reciprocal, which we did not examine. A study using experience sampling methodology found that, on days when employees had positive interactions, they experienced higher PA (Dimotakis et al., 2011). This suggests that affect and positive interactions might build two-way benefits: Individuals with higher PA may pursue resources by reaching out to their colleagues and in turn experience positive emotions. Similarly, while positive interactions predict higher engagement, this relationship may be reciprocal (Bakker \& Xanthopoulou, 2009), with more engaged employees seeking more opportunities to interact with others, perhaps as part of being motivated and getting work done. Future research should investigate the potentially reciprocal nature of these relationships.

Our study examined relationships between variables at the within-person level; personality, as a between-person variable, may also play a role in how these relationships unfold. For example, extroverted individuals may interact more frequently (Bakker \& Xanthopoulou, 2009), fostering engagement and subsequent recovery. In contrast, introverts may see interactions with colleagues as a draining demand. The role of personality in accumulating resources is an interesting avenue for future research.

\section{Practical Implications}


Examining the conditions under which engagement can flourish provides researchers and practitioners with a platform to facilitate positive change. Our results imply that physical recovery through sleep quality matters, potentially equipping individuals with positivity which they bring to work, enhancing their work interactions and subsequent engagement. Organizations could promote sleep quality by encouraging employees to adopt better bedtime routines (Loft \& Cameron, 2013) and proscribing afterhours work communications (Derks et al., 2014).

Our results suggest also that higher levels of positive interactions of colleagues create a positive environment where engagement can flourish. This is especially relevant given the shift toward team-based work environments (LePine, 2003). Engagement has contagious properties, where it crosses over from one worker to another (Bakker \& Xanthopoulou, 2009). Management can benefit from this interpersonal transmission by promoting positive interactions, setting up social events, buddy, and mentoring programs which may help the transference of engagement. However, this approach will only work to the extent that employees are engaged, and consequently may be risky in some environments (e.g., restructuring) where disengagement may spread. Lastly, while it has been suggested that "overengagement" may have undesired effects (Bakker et al., 2011), our results imply that engaged employees manage to leave work at work, and know how to unwind. Drawing on this, organizations should continue to foster engagement; both for the immediate impact on desirable performance and other outcomes, and also for the longer-term benefits, with engaged employees taking the motivational affective state experienced at work and bringing it to their evening activities, thereby fostering recovery.

\section{Conclusion}

Overall, this study contributes to extant research on daily fluctuations of engagement and recovery. Our study is novel in including positive collegial interactions as an antecedent of 
engagement. Furthermore, to our knowledge, our study is the first to examine antecedents and outcomes of engagement in a full 24 hour cycle. Our results suggest that, on mornings when individuals feel refreshed from a good quality sleep, they feel positive, and are more likely to reach out to their colleagues at work. A greater level of positive collegial interactions predicts higher engagement, suggesting such interactions act as a resource encouraging employees to immerse themselves in work. These positive work experiences do not end as the clock strikes five. To the contrary, on days when employees are engaged in their work, after work they report greater participation in activities that foster recovery.

\section{References}

Aguinis, H., Gottfredson, R. K., \& Joo, H. (2013). Best-practice recommendations for defining, identifying, and handling outliers. Organizational Research Methods, 16(2), 270-301. DOI: $10.1177 / 1094428112470848$

Âkerstedt, T., Kecklund, G., \& Axelsson, J. (2007). Impaired sleep after bedtime stress and worries. Biological Psychology, 76(3), 170-173. DOI:10.1016/j.biopsycho.2007.07.010

Antonakis, J., Bendahan, S., Jacquart, P., \& Lalive, R. (2010). On making causal claims: A review and recommendations. The Leadership Quarterly, 21(6), 1086-1120.

DOI:10.1016/j.leaqua.2010.10.010

Bakker, A. B., Albrecht, S. L., \& Leiter, M. P. (2011). Key questions regarding work engagement. European Journal of Work and Organizational Psychology, 20(1), 4-28. DOI:10.1080/1359432x.2010.485352

Bakker, A. B., \& Bal, M. P. (2010). Weekly work engagement and performance: A study among starting teachers. Journal of Occupational and Organizational Psychology, 83(1), 189206. DOI:10.1348/096317909X402596

Bakker, A. B., \& Demerouti, E. (2007). The job demands-resources model: State of the art. Journal of Managerial Psychology, 22(3), 309-328. DOI:10.1108/02683940710733115

Bakker, A. B., Shimazu, A., Demerouti, E., Shimada, K., \& Kawakami, N. (2014). Work engagement versus workoholism: A test of the spillover-crossover model. Journal of Managerial Psychology, 29(1), 63-80. DOI:10.1108/JMP-05-2013-0148 
Bakker, A. B., \& Xanthopoulou, D. (2009). The crossover of daily work engagement: Test of an actor-partner interdependence model. Journal of Applied Psychology, 94(6), 1562-1571. DOI: $10.1037 / \mathrm{a} 0017525$

Baumeister, R. F., \& Leary, M. R. (1995). The need to belong: Desire for interpersonal attachments as a fundamental human motivation. Psychological Bulletin, 117(3), 497529. DOI:10.1037/0033-2909.117.3.497

Binnewies, C., \& Fetzer, B. (2010). Affective states and affect regulation as antecedents of dynamic work engagement. In S. L. Albrecht (Eds.), Handbook of Employee Engagement: Perspectives, research, issues and practice (pp. 245-252). Cheltenham: Edward Elgar.

Binnewies, C., \& Sonnentag, S. (2013). The application of dairy methods to examine workers' daily recovery during off-job time. In A. B. Bakker, \& K. Daniels (Eds.), A day in a life of a happy worker. East Sussex: Psychology Press.

Binnewies, C., Sonnentag, S., \& Mojza, E. J. (2009). Daily performance at work: Feeling recovered in the morning as a predictor of day-level job performance. Journal of Organizational Behavior, 30(1), 67-93. DOI:10.1002/job.541

Bliese, P. D., \& Ployhart, R. E. (2002). Growth modeling using random coefficient models: Model building, testing, and illustrations. Organizational Research Methods, 5(4), 362387. DOI:10.1177/109442802237116

Bowling, N.A., Beehr, T.A., \& Swader, W.M. (2004). Giving and receiving social support at work: The roles of personality and reciprocity. Journal of Vocational Behvaior, 67(3), 476-489. DOI:10.1016/j.jvb.2004.08.004

Breevaart, K., Bakker, A. B., Demerouti, E., \& Hetland, J. (2012). The measurement of state work engagement: A multilevel factor analytic study. European Journal of Psychological Assessment, 28(4), 305-312. DOI:10.1027/1015-5759/a000111

Buysse, D. J., Reynolds III, C. F., Monk, T. H., Berman, S. R., \& Kupfer, D. J. (1989). The Pittsburgh sleep quality index: A new instrument for psychiatric practice and research. Psychiatry Research, 28(2), 193-213. DOI:10.1016/0165-1781(89)90047-4

Derks, D., TenBrummelhuis, L. L., Zecic, D., \& Bakker, A. B. (2014). Switching on and off ... : Does smartphone use obstruct the possibility to engage in recovery activities? European 
Journal of Work and Organizational Psychology, 23(1), 80-90.

DOI:10.1080/1359432X.2012.711013

Dimotakis, N., Scott, B. A., \& Koopman, J. (2011). An experience sampling investigation of workplace interactions, affective states, and employee well-being. Journal of Organizational Behavior, 32(4), 572-588. DOI:10.1002/job.722

Enders, C. K., \& Tofighi, D. (2007). Centering predictor variables in cross-sectional multilevel models: A new look at an old issue. Psychological Methods, 12(2), 121-138. DOI:10.1037/1082-989X.12.2.121

Fahlén, G., Knutsson, A., Peter, R., Âkerstedt, T., Nordin, M., Alfredsson, L., Westerholm, P. (2006). Effort-reward imbalance, sleep disturbances and fatigue. International Archives of Occupational and Environmental Health, 79(5), 371-378. DOI:10.1007/s00420-0050063-6

Fredrickson, B. L. (2004). The broaden-and-build theory of positive emotions. Philosophical Transactions: Biological Sciences, 359(1449), 1367-1377. DOI: 10.2307/4142140

Freeney, Y., \& Fellenz, M. R. (2013). Work engagement, job design and the role of the social context at work: Exploring antecedents from a relational perspective. Human Relations. DOI:10.1177/0018726713478245

Gardner, B. (2009). Incentivised snowballing. The Psychologist, 22, 768-769.

Garrosa, E., Moreno-Jiménez, B., Rodríguez-Muñoz, A., \& Rodríguez-Carvajal, R. (2011). Role stress and personal resources in nursing: A cross-sectional study of burnout and engagement. International Journal of Nursing Studies, 48(4), 479-489. DOI: 10.1016/j.ijnurstu.2010.08.004

Gorgievski, M. J., Bakker, A. B., \& Schaufeli, W. B. (2010). Work engagement and workaholism: Comparing the self-employed and salaried employees. The Journal of Positive Psychology, 5(1), 83-96. DOI:10.1080/17439760903509606

Hakanen, J. J., \& Schaufeli, W.B. (2012). Do burnout and work engagement predict depressive symptoms and life satisfaction? A three-wave seven-year prospective study. Journal of Affective Disorders, 141(2-3), 415-424. DOI: 10.1016/j.jad.2012.02.043

Halbesleben, J. R. B., Harvey, J., \& Bolino, M. C. (2009). Too engaged? A conservation of resrouces view of the relationship between work engagement and work interface with family. Journal of Applied Psychology, 94(6), 1452-1465. DOI:10.1037/a0017595 
Harmon-Jones, E., Gable, P. A., \& Price, T. F. (2013). Does negative affect always narrow and positive affect always broaden the mind? Considering the influence of motivational intensity on cognitive scope. Current Directions in Psychological Science, 22(4), 301307. DOI:10.1177/0963721413481353

Heaphy, E. D., \& Dutton, J. E. (2008). Positive social interactions and the human body at work: Linking organizations and physiology. Academy of Management Review, 33(1), 137-162. DOI:10.5465/amr.2008.27749365

Heck, R. H., Thomas, S. L., \& Tabata, L. N. (2013). Multilevel and longtitudinal modeling with IMB SPSS (2nd ed.). New York: Routledge.

Hobfoll, S. E. (1989). Conservation of resources: A new attempt at conceptualizing stress. American Psychologist, 44(3), 513-524. DOI:10.1037/0003-066X.44.3.513

Hobfoll, S. E. (2002). Social and psychological resources and adaptation. Review of General Psychology, 6(4), 307-324. DOI:10.1037/1089-2680.6.4.307

Hox, J. J. (2010). Multilevel analysis: Techniques and applications (2nd ed.). New York: Routledge.

Kepes, S., \& McDaniel, M. A. (2013). How trustworthy is the scientific literature in industrial and organizational psychology? Industrial and Organizational Psychology, 6(3), 252268. DOI:10.1111/iops.12045

Kucharczyk, E. R., Morgan, K., \& Hall, A. P. (2012). The occupational impact of sleep quality and insomnia symptoms. Sleep Medicine Reviews, 16(6), 547-559.

DOI:10.1016/j.smrv.2012.01.005

LePine, J. A. (2003). Team adaptation and postchange performance: Effects of team composition in terms of members' cognitive ability and personality. Journal of Applied Psychology, 88(1), 27-39. DOI:10.1037/0021-9010.88.1.27

Lim, S., Cortina, L. M., \& Magley, V. J. (2008). Personal and workgroup incivility: Impact on work and health outcomes. Journal of Applied Psychology, 93(1), 95-107. doi:10.1037/0021-9010.93.1.95

Loft, M. H., \& Cameron, L. D. (2013). Using mental imagery to deliver self-regulation techniques to improve sleep behaviors. Annals of Behavioral Medicine, 46(3), 260-272. DOI:10.1007/s12160-013-9503-9 
Methot, J. R., LePine, J. A., Podsakoff, N. P., \& Christian, J. S. (2016). Are workplace friendships a mixed blessing? Exploring tradeoffs of multiplex relationships and their associations with job performance. Personnel Psychology,69, 311-355.DOI: 10.1111/peps.12109

Newman, D. A. (2008). Missing data techniques and low response rates: The role of systematic nonresponse parameters. In C. E. Lance, \& R. J. Vandenberg (Eds.), Statistical and methodological myths and urban legends: Doctrine, verity and fable in the organizational and social sciences (pp. 7-36). New York: Routledge.

Nielsen, I. K., Jex, S. M., \& Adams, G. A. (2000). Development and validation of scores on a two-dimensional workplace friendship scale. Educational and Psychological Measurement, 60(4), 628-643. DOI:10.1177/00131640021970655

Ouweneel, E., LeBlanc, P. M., \& Schaufeli, W. B. (2012). Don't leave your heart at home: Gain cycles of positive emotions, resources, and engagement at work. Career Development International, 17(6), 537-556. DOI:10.1108/13620431211280123

Ouweneel, E., LeBlanc, P. M., Schaufeli, W. B., \& vanWijhe, C. I. (2012). Good morning, good day: A diary study on positive emotions, hope, and work engagement. Human Relations, 65(9), 1129-1154. DOI:10.1177/0018726711429382

Podsakoff, P. M., MacKenzie, S. B., \& Podsakoff, N. P. (2012). Sources of method bias in social science research and recommendations on how to control it. Annual Review of Psychology, 63(1), 539-569. DOI:10.1146/annurev-psych-120710-100452

Preacher, K. J., \& Selig, J. P. (2012). Advantages of Monte Carlo confidence intervals for the indirect effects. Communication Methods and Measures, 6(2), 77-98.

DOI:10.1080/19312458.2012.679848

Querstret, D., \& Cropley, M. (2012). Exploring the relationship between work-related rumination, sleep quality, and work-related fatigue. Journal of Occupational Health Psychology, 17(3), 341-353. DOI:10.1037/a0028552

Raudenbush, S. W., \& Bryk , A. S. (2002). Hierarchical linear models: Applications and data analysis methods (2nd ed.). Thousand Oaks, CA: Sage Publications.

Rodenbeck, A., Huether, G., Rüther, E., \& Hajak, G. (2002). Interactions between evening and nocturnal cortisol secretion and sleep parameters in patients with severe chronic primary insomnia. Neuroscience Letters, 324(2), 159-163. DOI:10.1016/S0304-3940(02)00192-1 
Rook, J. W., \& Zijlstra, F. R. H. (2006). The contribution of various types of activities to recovery. European Journal of Work and Organizational Psychology, 15(2), 218-240. DOI:10.1080/13594320500513962

Ryan, R. M., \& Deci, E. L. (2000). Self-determination theory and the facilitation of intrinsic motivation, social development, and well-being. American Psychologist, 55(1), 68-78. DOI:10.1037/0003-066x.55.1.68

Salanova, M., Agut, S., \& Peiró, J. M. (2005). Linking organizational resources and work engagement to employee performance and customer loyalty: The mediation of service climate. Journal of Applied Psychology, 90(6), 1217-1227. DOI:10.1037/00219010.90.6.1217

Sanz-Vergel, A. I., Demerouti, E., Moreno-Jiménez, B., \& Mayo, M. (2010). Work-family balance and energy: A day-level study on recovery conditions. Journal of Vocational Behavior, 76(1), 118-130. DOI: 10.1016/j.jvb.2009.07.001

Schaufeli, W. B., Bakker, A. B., \& Salanova, M. (2006). The measurement of work engagement with a short questionnaire: A cross-national study. Educational and Psychological Measurement, 66(4), 701-716. DOI:10.1177/0013164405282471

Schaufeli, W. B., Salanova, M., González-Romá, V., \& Bakker, A. B. (2002). The measurement of engagement and burnout: A two sample confirmatory factor analytic approach. Journal of Happiness Studies, 3(1), 71-92. DOI:10.1023/a:1015630930326

Schütze, R., Rees, C., Preece, M., \& Schütze, M. (2010). Low mindfulness predicts pain catastrophizing in a fear-avoidance model of chronic pain. PAIN, 148(1), 120-127. DOI:10.1016/j.pain.2009.10.030

Selig, J. P., \& Preacher, K. J. (2008). Monte Carlo method for assessing mediation: An interactive tool for creating confidence intervals for indirect effects. Retrieved from: http://quantpsy.org/

Sonnentag, S. (2003). Recovery, work engagement, and proactive behavior: A new look at the interface between nonwork and work. Journal of Applied Psychology, 88(3), 518-528. DOI:10.1037/0021-9010.88.3.518

Sonnentag, S., \& Binnewies, C. (2013). Daily affect spillover from work to home: Detachment from work and sleep as moderators. Journal of Vocational Behavior, 83(2), 198-208. DOI:10.1016/j.jvb.2013.03.008 
Sonnentag, S., Binnewies, C., \& Mojza, E. J. (2008). " Did you have a nice evening?" A daylevel study on recovery experiences, sleep, and affect. Journal of Applied Psychology, 93(3), 674-684. DOI:10.1037/0021-9010.93.3.674

Sonnentag, S., \& Fritz, C. (2007). The recovery experience questionnaire: Development and validation of a measure for assessing recuperation and unwinding from work. Journal of Occupational Health Psychology, 12(3), 204-221. DOI: 10.1037/1076-8998.12.3.204

Sonnentag, S., Mojza, E. J., Demerouti, E., \& Bakker, A. B. (2012). Reciprocal relations between recovery and work engagement: The moderating role of job stressors. Journal of Applied Psychology, 97(4), 842-853. DOI:10.1037/a0028292

Spector, P. E., \& Brannick, M. T. (2011). Methodological urban legends: The misuse of statistical control variables. Organizational Research Methods, 14(2), 287-305. DOI:10.1177/1094428110369842

Steptoe, A., Dockray, S., \& Wardle, J. (2009). Positive affect and psychobiological processes relevant to health. Journal of Personality, 77(6), 1747-1776. DOI:10.1111/j.14676494.2009.00599.x

Tabachnick, B. G., \& Fidell, L. S. (2013). Using multivariate statistics (6th ed.). Upper Saddle River, NJ: Pearson.

ten Brummelhuis, L. L., \& Bakker, A. B. (2012a). A resource perspective on the work-home interface: The work-home resources model. American Psychologist, 67(7), 545-556. DOI: $10.1037 / \mathrm{a} 0027974$

ten Brummelhuis, L. L., \& Bakker, A. B. (2012b). Staying engaged during the week: The effect of off-job activities on next day work engagement. Journal of Occupational Health Psychology, 17(4), 445-455. DOI:10.1037/a0029213

Thompson, E. R. (2007). Development and validation of an internationally reliable short-form of the positive and negative affect schedule (PANAS). Journal of Cross-Cultural Psychology, 38(2), 227-242. DOI:10.1177/0022022106297301

Vahle-Hinz, T., Bamberg, E., Dettmers, J., Friedrich, N., \& Keller, M. (2014). Effects of work stress on work-related rumination, restful sleep, and nocturnal heart rate variability experienced on workdays and weekends. Journal of Occupational Health Psychology, 19(2), 217-230. DOI:10.1037/a0036009 
Weigold, A., Weigold, I. K., \& Russell, E. J. (2013). Examination of the equivalence of selfreport survey-based paper-and-pencil and internet data collection methods. Psychological Methods, 18(1), 53-70. DOI: 10.1037/a0031607

Westman, M. (2001). Stress and strain crossover. Human Relations, 54(6), 717-751. DOI:10.1177/0018726701546002

Xanthopoulou, D., Bakker, A. B., Demerouti, E., \& Schaufeli, W. B. (2007). The role of personal resources in the job demands-resources model. International Journal of Stress Management, 14(2), 121-141. Xanthopoulou, D., Bakker, A., Heuven, E., Demerouti, E., \& Schaufeli, W. B. (2008). Working in the sky: A diary study on work engagement among flight attendants. Journal of Occupational Health Psychology, 13(4), 345-356. DOI:10.1037/1076-8998.13.4.345

Xanthopoulou, D., Bakker, A. B., Demerouti, E., \& Schaufeli, W. B. (2009a). Reciprocal relationships between job resources, personal resources, and work engagement. Journal of Vocational Behavior, 74(3), 235-244. DOI: 10.1016/j.jvb.2008.11.003

Xanthopoulou, D., Bakker, A. B., Demerouti, E., \& Schaufeli, W. B. (2009b). Work engagement and financial returns: A diary study on the role of job and personal resources. Journal of Occupational and Organizational Psychology, 82(1), 183-200.

DOI: $10.1348 / 096317908 \times 285633$

Xanthopoulou, D., Bakker, A. B., Demerouti, E., \& Schaufeli, W. B. (2012). A diary study on the happy worker: How job resources relate to positive emotions and personal resources. European Journal of Work and Organizational Psychology, 21(4), 489-517. DOI:10.1080/1359432x.2011.584386

Footnotes

${ }^{1}$ In New Zealand, Pasifika is used to identify persons whose families originally came from islands in the Pacific (e.g., Samoa, Tonga).

${ }^{2}$ Upon model building, negative affect was included as a control in Models 2 and 3 when predicting night-time recovery with engagement. Results were very similar. There is a general disagreement amongst researchers on whether or not to control for negative affect (Spector \& Brannick, 2011). Because the results were very similar, state negative affect was excluded from the final analyses. 
${ }^{3}$ Thanks to a reviewer for suggesting that we conduct additional mediation analyses to explore the relationship between friendship and recovery via engagement. 
RESTED, FRIENDLY, AND ENGAGED

Table 1

Means, standard deviations, Cronbach's alphas, intraclass correlations, and intercorrelations between the study variables.

\begin{tabular}{|c|c|c|c|c|c|c|c|c|c|c|c|c|c|c|c|c|c|}
\hline & & $M^{a}$ & $S D^{a}$ & $M^{b}$ & $S D^{b}$ & $\alpha$ & $1-\mathrm{ICC}$ & 1 & 2 & 3 & 4 & 5 & 6 & 7 & 8 & 9 & 10 \\
\hline 1 & General positive affect & 3.74 & .52 & - & - & .61 & - & - & & & & & & & & & \\
\hline 2 & General PCI & 4.34 & .58 & - & - & .80 & - & $.21^{*}$ & - & & & & & & & & \\
\hline 3 & General engagement & 4.04 & .89 & - & - & .91 & - & $.52^{* *}$ & $.22^{*}$ & - & & & & & & & \\
\hline 4 & General recovery & 3.57 & .65 & - & - & .88 & - & $.36^{* *}$ & $.24^{*}$ & .15 & - & & & & & & \\
\hline 5 & Sleep duration & 7.01 & .82 & 7.01 & 1.24 & & - & .13 & .20 & .13 & .14 & - & $.59^{* *}$ & $.12^{*}$ & $.17^{* *}$ & $.16^{* *}$ & $.19^{* *}$ \\
\hline 6 & Sleep quality & 3.85 & .88 & 3.87 & 1.27 & & 66.5 & .03 & .02 & .10 & .16 & $.60^{* *}$ & - & $.25^{* *}$ & $.18^{* *}$ & $.24^{* *}$ & $.26^{* *}$ \\
\hline 7 & Day-level positive affect & 3.10 & .76 & 3.10 & 0.92 & .88 & 40.7 & $.45^{* *}$ & .15 & $.48^{* *}$ & .02 & .03 & .14 & - & $.31^{* *}$ & $.53^{* *}$ & .06 \\
\hline 8 & Day-level PCI & 4.20 & .73 & 4.19 & 0.87 & .85 & 37.3 & $.31^{* *}$ & $.67^{* *}$ & $.30^{* *}$ & $.33^{* *}$ & $.26^{*}$ & $.25^{*}$ & $.31^{* *}$ & - & $.36^{* *}$ & $.31^{* *}$ \\
\hline 9 & Day-level engagement & 3.72 & .97 & 3.74 & 1.10 & .94 & 32.2 & $.38^{* *}$ & .18 & $.74^{* *}$ & .11 & .14 & $.24^{*}$ & $.54^{* *}$ & $.38^{* *}$ & - & $.17^{* *}$ \\
\hline 10 & Day-level recovery & 3.36 & .69 & 3.35 & 0.82 & .91 & 38.8 & .18 & .15 & .02 & $.65^{* *}$ & $.27^{*}$ & $.38^{* *}$ & .07 & $.38^{* *}$ & .14 & - \\
\hline
\end{tabular}

Note. PCI = positive collegial interactions. Person-level $(N=69)$ correlations are displayed below the diagonal line. At person level, day-level variables were averaged across 5 measurement occasions. Day-level $(N=336)$ correlations are displayed above the diagonal line.

${ }^{\mathrm{a}}=$ means and standard deviations at person level. ${ }^{\mathrm{b}}=$ means and standard deviations at day-level. 1 -ICC $=$ percentage of variance at day-level $(\mathrm{ICC}=$ variance at person-level / (variance at person-level + variance at day-level).

$* p<.05, * * p<.01$ 
Table 2

Multilevel estimates for models predicting a lagged effect of recovery on sleep quality (Hypothesis 1a)

\begin{tabular}{|c|c|c|c|c|c|c|c|c|c|}
\hline \multirow[b]{2}{*}{ Variables } & \multicolumn{3}{|c|}{ Null Model } & \multicolumn{3}{|c|}{ Model 1} & \multicolumn{3}{|c|}{ Model 2} \\
\hline & Estimate & $S E$ & $t$ & Estimate & $S E$ & $t$ & Estimate & $S E$ & $t$ \\
\hline Intercept & 3.86 & 0.10 & $36.77^{* * *}$ & 3.86 & 0.10 & $36.78^{* * *}$ & 3.86 & 0.11 & $33.87^{* * *}$ \\
\hline Weekday & & & & 0.12 & 0.03 & $3.86^{* * * *}$ & 0.13 & 0.04 & $3.01^{* *}$ \\
\hline $\begin{array}{l}\text { Sleep duration } \\
\text { (morning) }\end{array}$ & & & & 0.61 & 0.05 & $12.47^{* * *}$ & 0.72 & 0.06 & $12.20^{* * *}$ \\
\hline $\begin{array}{l}\text { Recovery lag } \\
\text { (night-time) }\end{array}$ & & & & & & & 0.22 & 0.11 & $1.97^{\#}$ \\
\hline$-2 \times \log (\mathrm{lh})$ & & 1061.19 & & & 935.93 & & & 709.73 & \\
\hline$\Delta-2 \times \log$ & & & & & $125.26^{* * *}$ & & & $226.20^{* * * *}$ & \\
\hline \multirow[t]{2}{*}{$d f$} & & & & & 2 & & & 1 & \\
\hline & & & & & & $\mathrm{R}^{2}$ & & & $\mathrm{R}^{2}$ \\
\hline $\begin{array}{l}\text { Level } 1 \text { day- } \\
\text { level variance } \\
\text { (SE) }\end{array}$ & 1.068 & 0.092 & & 0.668 & 0.058 & $37.4 \%$ & 0.598 & 0.062 & $44 \%$ \\
\hline $\begin{array}{l}\text { Level } 2 \\
\text { person-level } \\
\text { variance (SE) }\end{array}$ & 0.539 & 0.130 & & 0.622 & 0.130 & $0 \%$ & 0.670 & 0.147 & $0 \%$ \\
\hline
\end{tabular}


Table 3

Multilevel estimates for models predicting morning PA (Hypothesis $1 b$ )

\begin{tabular}{|c|c|c|c|c|c|c|c|c|c|}
\hline \multirow[b]{2}{*}{ Variables } & \multicolumn{3}{|c|}{ Null Model } & \multicolumn{3}{|c|}{ Model 1} & \multicolumn{3}{|c|}{ Model 2} \\
\hline & Estimate & $S E$ & $t$ & Estimate & $S E$ & $t$ & Estimate & $S E$ & $t$ \\
\hline Intercept & 3.10 & 0.09 & $34.18^{* * * *}$ & 3.09 & 0.08 & $38.14^{* * *}$ & 3.08 & 0.08 & $36.27^{* * * *}$ \\
\hline Weekday & & & & 0.00 & 0.02 & -0.19 & -.01 & 0.03 & -0.43 \\
\hline Sleep duration & & & & 0.14 & 0.03 & $4.04^{* * *}$ & 0.07 & 0.05 & 1.34 \\
\hline $\begin{array}{l}\text { Positive affect } \\
\text { (general) }\end{array}$ & & & & 0.65 & 0.16 & $4.18^{* * *}$ & 0.69 & 0.16 & $4.25^{* * *}$ \\
\hline $\begin{array}{l}\text { Recovery lag } \\
\text { (night-time) }\end{array}$ & & & & & & & 0.01 & 0.07 & 0.09 \\
\hline $\begin{array}{l}\text { Sleep quality } \\
\text { (morning) }\end{array}$ & & & & & & & 0.23 & 0.05 & $4.91^{* * *}$ \\
\hline$-2 \times \log (\mathrm{lh})$ & & 735.64 & & & 703.68 & & & 511.78 & \\
\hline$\Delta-2 \times \log$ & & & & & $31.96^{* * * *}$ & & & $191.90^{* * *}$ & \\
\hline \multirow[t]{2}{*}{$d f$} & & & & & 3 & & & 2 & \\
\hline & & & & & & $\mathrm{R}^{2}$ & & & $\mathrm{R}^{2}$ \\
\hline $\begin{array}{l}\text { Level } 1 \text { day- } \\
\text { level variance } \\
\text { (SE) }\end{array}$ & 0.340 & 0.029 & & 0.320 & 0.028 & $5.9 \%$ & 0.257 & 0.027 & $24.4 \%$ \\
\hline $\begin{array}{l}\text { Level } 2 \text { person- } \\
\text { level variance } \\
\text { (SE) }\end{array}$ & 0.496 & 0.096 & & 0.386 & 0.077 & $22.3 \%$ & 0.413 & 0.084 & $16.7 \%$ \\
\hline
\end{tabular}


Table 4

Multilevel estimates for models predicting afternoon positive interactions (Hypothesis 2a)

\begin{tabular}{|c|c|c|c|c|c|c|c|c|c|}
\hline \multirow[b]{2}{*}{ Variables } & \multicolumn{3}{|c|}{ Null Model } & \multicolumn{3}{|c|}{ Model 1} & \multicolumn{3}{|c|}{ Model 2} \\
\hline & Estimate & $S E$ & $t$ & Estimate & $S E$ & $t$ & Estimate & $S E$ & $t$ \\
\hline $\begin{array}{l}\text { Intercept } \\
\text { Weekday }\end{array}$ & 4.19 & 0.09 & $48.06^{* * *}$ & $\begin{array}{r}4.16 \\
-0.01\end{array}$ & $\begin{array}{l}0.07 \\
0.02\end{array}$ & $\begin{array}{l}63.79^{* * * *} \\
-0.65\end{array}$ & $\begin{array}{l}4.15 \\
-0.01\end{array}$ & $\begin{array}{l}0.07 \\
0.02\end{array}$ & $\begin{array}{c}62.99^{* * * *} \\
-0.34\end{array}$ \\
\hline $\begin{array}{l}\text { PCI } \\
\text { (general) }\end{array}$ & & & & 0.84 & 0.11 & $7.48^{* * * *}$ & 0.84 & 0.11 & $7.36^{* * *}$ \\
\hline $\begin{array}{l}\text { Positive affect } \\
\text { (morning) }\end{array}$ & & & & & & & 0.13 & 0.06 & $2.31^{*}$ \\
\hline$-2 \times \log (\mathrm{lh})$ & & 649.45 & & & 607.93 & & & 596.21 & \\
\hline$\Delta-2 \times \log$ & & & & & $41.52^{* * *}$ & & & $11.72^{* * *}$ & \\
\hline \multirow[t]{2}{*}{$d f$} & & & & & 2 & & & 1 & \\
\hline & & & & & & $\mathrm{R}^{2}$ & & & $\mathrm{R}^{2}$ \\
\hline $\begin{array}{l}\text { Level } 1 \text { day- } \\
\text { level variance } \\
\text { (SE) }\end{array}$ & 0.275 & 0.024 & & 0.274 & 0.024 & $0 \%$ & 0.265 & 0.023 & $3.6 \%$ \\
\hline $\begin{array}{l}\text { Level } 2 \text { person- } \\
\text { level variance } \\
\text { (SE) }\end{array}$ & 0.464 & 0.089 & & 0.230 & 0.049 & $50.4 \%$ & 0.239 & 0.050 & $48.5 \%$ \\
\hline
\end{tabular}

Note. $\mathrm{PCI}=$ positive collegial interactions. ${ }^{*} * * p<.001, * * p<.01, * p<.05$ 
Table 5

Multilevel estimates for models predicting day-level engagement (Hypothesis $2 b$ )

\begin{tabular}{|c|c|c|c|c|c|c|c|c|c|}
\hline \multirow[b]{2}{*}{ Variables } & \multicolumn{3}{|c|}{ Null Model } & \multicolumn{3}{|c|}{ Model 1} & \multicolumn{3}{|c|}{ Model 2} \\
\hline & Estimate & $S E$ & $t$ & Estimate & $S E$ & $t$ & Estimate & $S E$ & $t$ \\
\hline $\begin{array}{l}\text { Intercept } \\
\text { Weekday }\end{array}$ & 3.72 & 0.12 & $32.19^{* * *}$ & $\begin{array}{l}3.71 \\
0.01\end{array}$ & $\begin{array}{l}0.08 \\
0.03\end{array}$ & $\begin{array}{c}48.24^{* * *} \\
0.22\end{array}$ & $\begin{array}{l}3.73 \\
0.02\end{array}$ & $\begin{array}{l}0.08 \\
0.02\end{array}$ & $\begin{array}{c}48.42^{* * * *} \\
0.75\end{array}$ \\
\hline $\begin{array}{l}\text { Engagement } \\
\text { (general) }\end{array}$ & & & & 0.81 & 0.09 & $9.30^{* * *}$ & 0.81 & 0.09 & $9.40^{* * * *}$ \\
\hline $\begin{array}{l}\text { Positive affect } \\
\text { (morning) }\end{array}$ & & & & & & & 0.48 & 0.06 & $7.76^{* * * *}$ \\
\hline $\begin{array}{l}\text { PCI } \\
\text { (afternoon) }\end{array}$ & & & & & & & 0.22 & 0.07 & $3.28^{* *}$ \\
\hline$-2 \times \log (\mathrm{lh})$ & & 751.88 & & & 695.79 & & & 601.19 & \\
\hline$\Delta-2 \times \log$ & & & & & $56.09^{* * * *}$ & & & $94.60^{* * *}$ & \\
\hline \multirow[t]{2}{*}{$d f$} & & & & & 2 & & & 2 & \\
\hline & & & & & & $\mathrm{R}^{2}$ & & & $\mathrm{R}^{2}$ \\
\hline $\begin{array}{l}\text { Level } 1 \text { day- } \\
\text { level variance } \\
\text { (SE) }\end{array}$ & 0.394 & 0.036 & & 0.394 & 0.036 & $0 \%$ & 0.291 & 0.027 & $26.1 \%$ \\
\hline $\begin{array}{l}\text { Level } 2 \text { person- } \\
\text { level variance } \\
\text { (SE) }\end{array}$ & 0.830 & 0.157 & & 0.316 & 0.069 & $61.9 \%$ & 0.334 & 0.069 & $59.7 \%$ \\
\hline
\end{tabular}

Note. $\mathrm{PCI}=$ positive collegial interactions. ${ }^{* * *} p<.001, * * p<.01,{ }^{*} p<.05$ 
Table 6

Confidence intervals, direct and indirect effects for mediation (Hypotheses $2 c, 2 d$ and additional analyses)

\begin{tabular}{|c|c|c|c|c|c|c|c|}
\hline \multirow{2}{*}{$x \rightarrow m \rightarrow y$} & \multicolumn{7}{|c|}{$95 \%$ confidence intervals } \\
\hline & $\mathrm{a}(S E)$ & $\mathrm{b}(S E)$ & $\mathrm{a} * \mathrm{~b}$ & $\begin{array}{l}\text { Lower } \\
\text { bound }\end{array}$ & $\begin{array}{l}\text { Upper } \\
\text { bound }\end{array}$ & $c$ & $c^{\prime}$ \\
\hline Positive affect $\rightarrow$ PCI $\rightarrow$ engagement & $.13(.06)$ & $.22(.07)$ & .03 & .0033 & $.0639^{*}$ & $.52(.06)^{* * * *}$ & .55 \\
\hline Sleep quality $\rightarrow$ positive affect $\rightarrow$ engagement & $.24(.04)$ & $.50(.07)$ & .12 & .0729 & $.1709^{*}$ & $.13(.04)^{* *}$ & .25 \\
\hline Sleep quality $\rightarrow$ positive affect $\rightarrow$ PCI & $.24(.04)$ & $.14(.06)$ & .03 & .0050 & $.0663^{*}$ & $.02(.03)$ & .05 \\
\hline $\mathrm{PCI} \rightarrow$ engagement $\rightarrow$ recovery & $.30(.07)$ & $.14(.05)$ & .04 & .0108 & $.0758^{*}$ & $.17(.06)^{* *}$ & .21 \\
\hline
\end{tabular}

Note . $\mathrm{PCI}=$ positive collegial interactions. The estimates and their standard errors (SE) presented are drawn from Tables 2, 3, 4, 5, Model 2.

$\mathrm{a}=$ parameter estimate for the relationship between $x$ and $m ; \mathrm{b}=$ parameter estimate for the relationship $m$ and $y$, taking into account $x$ in the model; $\mathrm{c}=$ parameter estimate for the relationship between $x$ and $y$ (direct effect). $\mathrm{a}^{*} \mathrm{~b}=$ estimate for the indirect relationship of $x$ and $y$, via $m$ (indirect effect). $\mathrm{c}^{\prime}=$ product of $a^{*} b$ and $c$ (total effect).

$* * * p<.001, * * p<.01, * p<.05$ 
Table 7

Multilevel estimates for models predicting night-time recovery (Hypothesis 3)

\begin{tabular}{|c|c|c|c|c|c|c|c|c|c|}
\hline \multirow[b]{2}{*}{ Variables } & \multicolumn{3}{|c|}{ Null Model } & \multicolumn{3}{|c|}{ Model 1} & \multicolumn{3}{|c|}{ Model 2} \\
\hline & Estimate & $S E$ & $t$ & Estimate & $S E$ & $t$ & Estimate & $S E$ & $t$ \\
\hline Intercept & 3.36 & 0.08 & $40.56^{* * *}$ & 3.36 & 0.06 & $53.64^{* * *}$ & 3.36 & 0.07 & $53.91^{* * * *}$ \\
\hline Day & & & & 0.04 & 0.02 & 1.78 & 0.03 & 0.02 & 1.68 \\
\hline $\begin{array}{l}\text { Recovery } \\
\text { (general) }\end{array}$ & & & & 0.69 & 0.10 & $7.15^{* * * *}$ & 0.68 & 0.10 & $7.11^{* * * *}$ \\
\hline $\begin{array}{l}\text { Engagement } \\
\text { (day-level) }\end{array}$ & & & & & & & 0.16 & 0.05 & $3.12^{* *}$ \\
\hline$-2 \times \log (\mathrm{lh})$ & & 618.27 & & & 576.88 & & & 553.71 & \\
\hline$\Delta-2 \times \log$ & & & & & $41.39^{* * * *}$ & & & $23.17^{* * *}$ & \\
\hline \multirow[t]{2}{*}{$d f$} & & & & & 2 & & & 1 & \\
\hline & & & & & & $\mathrm{R}^{2}$ & & & $\mathrm{R}^{2}$ \\
\hline $\begin{array}{l}\text { Level } 1 \text { day- } \\
\text { level variance } \\
\text { (SE) }\end{array}$ & 0.262 & 0.024 & & 0.259 & 0.023 & $1.1 \%$ & 0.248 & 0.023 & $5.3 \%$ \\
\hline $\begin{array}{l}\text { Level } 2 \text { person- } \\
\text { level variance } \\
\text { (SE) }\end{array}$ & 0.414 & 0.081 & & 0.212 & 0.046 & $48.7 \%$ & 0.210 & 0.046 & $49.3 \%$ \\
\hline
\end{tabular}

